OPEN ACCESS

Edited by:

Marcio L. Rodrigues,

Oswaldo Cruz Foundation, Brazil

Reviewed by:

Isaac Kirubakaran Sundar,

University of Rochester, USA

Celio Geraldo Freire De Lima,

Federal University of Rio de Janeiro,

Brazil

*Correspondence:

Anna Vecchiarell

anna.vecchiarelli@unipg.it

Specialty section:

This article was submitted to

Fungi and Their Interactions,

a section of the journal

Frontiers in Microbiology

Received: 08 April 2016

Accepted: 25 May 2016

Published: 08 June 2016

Citation:

Kenno S, Perito S, Mosci P, Vecchiarelli $A$ and Monari C (2016)

Autophagy and Reactive Oxygen

Species Are Involved in Neutrophil Extracellular Traps Release Induced

by C. albicans Morphotypes.

Front. Microbiol. 7:879.

doi: 10.3389/fmicb.2016.00879

\section{Autophagy and Reactive Oxygen Species Are Involved in Neutrophil Extracellular Traps Release Induced by C. albicans Morphotypes}

\author{
Samyr Kenno ${ }^{1}$, Stefano Perito ${ }^{2}$, Paolo Mosci $^{3}$, Anna Vecchiarelli ${ }^{2 *}$ and Claudia Monari ${ }^{2}$ \\ ${ }^{1}$ Division of Hygiene and Medical Microbiology, Innsbruck Medical University, Innsbruck, Austria, ${ }^{2}$ Microbiology Section, \\ Department of Experimental Medicine, University of Perugia, Perugia, Italy, ${ }^{3}$ Internal Medicine, Department of Veterinary \\ Medicine, University of Perugia, Perugia, Italy
}

Neutrophil extracellular traps (NETs) are a combination of DNA fibers and granular enzymes, such as elastase and myeloperoxidase. In this study, we demonstrate that Candida albicans hyphal (CAH) cells and yeast (CAY) cells induce differential amounts, kinetics and mechanisms of NET release. CAH cells induced larger quantities of NET compared to CAY cells and can stimulate rapid NET formation up to $4 \mathrm{~h}$ of incubation. CAY cells are, also, able to induce rapid NET formation, but this ability was lost at $4 \mathrm{~h}$. Both reactive oxygen species (ROS) and autophagy are implicated in NET induced by $\mathrm{CAH}$ and $\mathrm{CAY}$ cells, but with a time-different participation of these two mechanisms. In particular, in the early phase (15 min) CAH cells stimulate NET via autophagy, but not via ROS, while CAY cells induce NET via both autophagy and ROS. At 4 h, only CAH cells stimulate NET formation using autophagy as well as ROS. Finally, we demonstrate that NET release, in response to CAH cells, involves NF-kB activation and is strongly implicated in hyphal destruction.

Keywords: NET, autophagy, ROS, C. albicans, neutrophils

\section{INTRODUCTION}

Candida albicans is both the most common fungal commensal and the most important fungal pathogen causing mucosal and disseminated candidiasis in at risk population, especially immunocompromised patients. Phagocytes, particularly neutrophils, are believed to be the most effective cell type for clearing Candida infection (van 't Wout et al., 1988; Cheng et al., 2012). It has been reported that the success of antifungal treatment in transplant recipients is, also, dependent on neutrophil recovery (Safdar et al., 2007). To disseminate in the host, C. albicans has evolved many different virulence traits. Among them, the ability to switch from yeast to a filamentous form (hyphae), in response to external signals, is a dominant one. This transition is important for invasion and tissue damage (Gow, 2002; Whiteway and Oberholzer, 2004).

Neutrophils are able to kill C. albicans, yeast and hyphal cells. However, the mechanism of killing is considered to be quite different because yeast forms are ingested and killed, while the hyphal forms are too large to be engulfed and killed intracellularly. Neutrophil antimicrobial mechanisms are well studied and include phagocytosis, degranulation, production of reactive oxygen species (ROS), antimicrobial peptides secretion and extrusion of neutrophil extracellular traps (NETs; Brinkmann et al., 2004; Nathan, 2006; Chen and Junger, 2012). 
Neutrophil extracellular traps are a combination of DNA fibers and granular enzymes (Brinkmann et al., 2004), such as elastase and myeloperoxidase, that are released, mainly, via the cell-death program named NETosis by Steinberg and Grinstein (2007). Activation of NETosis has been shown to involve NADPH oxidase (Nox2)-mediated oxidative burst (Babior, 1999), disintegration of the nuclear envelope and most granule membranes, which, together, result in massive vacuolization (Fuchs et al., 2007), intracellular de-condensation of nuclear chromatin (Wang et al., 2009), and eventually formation of NET (Brinkmann et al., 2004). NET formation is known to be stimulated by some cytokines (e.g., Interleukin-8), bacterial products (lipopolysaccharide, LPS) and, importantly, by clinically relevant bacteria such as Shigella flexneri (Brinkmann et al., 2004), Staphylococcus aureus (Brinkmann et al., 2004), Streptococcus pneumoniae (Brinkmann and Zychlinsky, 2007), and by fungi including C. albicans and Aspergillus fumigatus (Urban et al., 2006, 2009; Bruns et al., 2010; Branzk et al., 2014). Recently, rapid extrusion of NETs in response to microorganisms, such as S. aureus (Pilsczek et al., 2010) and C. albicans (Byrd et al., 2013) has been reported to occur without cell death.

It has been, recently, demonstrated that NET formation, could be secondary to superoxide production and autophagy (Remijsen et al., 2011). Autophagy is a well-conserved, essential intracellular degradation process, known to regulate protein and organelle turnover in many cells (Levine and Kroemer, 2008). In addition, autophagy has been implicated, also, in cell death (Kroemer et al., 2009). Recent data provide evidence for autophagy's contribution to distinct antimicrobial strategies, rather than to neutrophil development or survival. An autophagy response is triggered, for example, by group A Streptococcus (Nakagawa et al., 2004), Mycobacterium tuberculosis (Gutierrez et al., 2004), Salmonella enterica (Birmingham and Brumell, 2006), Toxoplasma gondii (Ling et al., 2006), Aspergillus niger (Nitsche et al., 2013) Cryptococcus neoformans and C. albicans (Nicola et al., 2012).

Although it is demonstrated that C. albicans induces NETrelease (Urban et al., 2006), the molecular mechanisms involved in this process have yet to be completely elucidated. Recently it has been demonstrated that $C$. albicans spores, both live and heat killed, induce autophagy (Kanayama and Shinohara, 2016), however, its role is not described in NET induction by different morphotypes of $C$. albicans. The aim of this study was to gain some insight into the mechanisms involved in the NETs formation, including the role of autophagy, and to differentiate the relevance of hyphal and yeast forms, of the fungus, during this process.

\section{MATERIALS AND METHODS}

\section{Reagents and Media}

RPMI 1640 medium with L-glutamine, without phenol red and sodium bicarbonate were obtained from Sigma (St Louis, MO, USA). Rabbit polyclonal antibodies to neutrophil elastase $(\mathrm{H}-$ 57) and to actin (H300) and goat antibody to rabbit IgGTR conjugated were obtained from Santa Cruz Biotechnology (Dallas, TX, USA). Rabbit monoclonal antibody to human
LC3B (D11), rabbit polyclonal antibodies to human pNF$\kappa B$ p65 (Ser 536) and to human NF-кB p65 (C-20) were purchase from Cell Signaling Technology (Danvers, MA, USA). PE-conjugated rabbit monoclonal antibody (IgG) to human pNF-кBp65 (Ser 536) and rabbit monoclonal antibody isotype-matched control (PE-conjugated) were obtained from Cell Signaling Technology (Danvers, MA, USA). SYTOXgreen Nucleic Acid Stain was purchase from Invitrogen (Carlsbad, CA, USA). Human serum (HS) was obtained from MP biomedical (Santa Anna, CA, USA). Normal goat serum was obtained from Jackson Immuno Research (Newmarket, UK). Cold water fish gelatin, bovine serum albumin (BSA), Wortmannin (WT), N-acetyl-L-cysteine (NAC), Tween 20, 5ammino-2,3-diidro-1,4-ftalazindione (luminol), water DNase free, phosphate buffered saline (PBS), DNAse-1 and Cytochalasin D (cytD) were purchase from Sigma-Aldrich (St Louis, MO, USA). The NF-кB inhibitor, (E)-3-[4-t-Butylphenylsulfonyl]-2propenenitrile (BAY 11-7082), was obtained from Santa Cruz Biotechnology. Mammalian protein extraction reagent (M-PER) was purchased from Thermo Scientific (Rockford, IL, USA). Ficoll-Paque PREMIUM was obtained from General Healthcare (Buckinghamshire, UK).

\section{Isolation of Human Neutrophils}

Heparinized venous blood from healthy donors was diluted with RPMI 1640, and mononuclear cells were separated by FicollPaque density gradient centrifugation (Monari et al., 2002). The pellet containing neutrophils and erythrocytes was treated with hypotonic saline to lyse the erythrocytes. Granulocytes were collected by centrifugation, washed twice in RPMI 1640, counted, and adjusted to the desired concentration. The purity of neutrophils (PMNs) isolated by this method was always $>98 \%$, as determined by Giemsa staining. PMNs viability, evaluated after $18 \mathrm{~h}$ of incubation, was $>98 \%$ in all determinations by a trypan blue dye exclusion test.

\section{Candida albicans}

The strains of $C$. albicans used in this study were C. albicans virulent strain CA-6, isolated from clinical specimen (Vecchiarelli et al., 1988), and C. albicans (CA1398) carrying the ACT1pgLUC59 fusion (gLUC59). The gLUC59 luciferase reporter has previously been described (Pietrella et al., 2012).

Candida albicans was cultured at $30^{\circ} \mathrm{C}$ in yeast extractpeptone-dextrose (YPD) broth overnight under slight agitation. Yeast cells, grown to stationary phase, were harvested from overnight YPD culture and resuspended to a final concentration of $5 \times 10^{7}$ cells $/ \mathrm{ml}$ in YPD to induce yeast form, or in RPMI$16402 \%$ glucose to induce hyphal form for $4 \mathrm{~h}$ at $37^{\circ} \mathrm{C}$. The cells were washed twice, counted on a hemocytometer, and adjusted to the desired concentration. Hyphal form was counted six times to overcome the problem of hyphae clumping (Urban et al., 2006).

\section{Detection of Neutrophil Extracellular Traps (NETs)}

Staining with the non-cell-permeable DNA dye SYTOXgreen was used to study the kinetics of NET formation (Kirchner 
et al., 2012). Human neutrophils $\left(2 \times 10^{6} / \mathrm{ml}\right)$ in NET Medium (RPMI-1640 modified without phenol red and sodium hydrogen, Hepes $10 \mathrm{Mm}$ ), were seeded to a cellstar 96-well plate and incubated, for $15 \mathrm{~min}$ and $4 \mathrm{~h}$ at $37^{\circ} \mathrm{C}$ and $5 \% \mathrm{CO}_{2}$, alone or with pre-opsonized (Urban et al., 2006) C. albicans hyphae (CAH), live (CALY) or heat inactivated yeast (CAIY; E:T = 1:2). To detect the extracellular DNA of NETs, SYTOXgreen $(2,5 \mu \mathrm{M}$; excitation: $488 \mathrm{~nm}$, emission: $510 \mathrm{~nm}$ ) was added to co-cultures and the fluorescence of NET-bound SYTOXgreen was analyzed using an infinite 200 reader (TECAN Infinite M200). In selected experiments, neutrophils, in NET Medium, were incubated alone or with CALY or CAIY at $37^{\circ} \mathrm{C}$ and $5 \% \mathrm{CO}_{2}$. After $15 \mathrm{~min}$ of incubation the medium, of PMNs-CAIY co-cultures, was replaced with supernatants from PMNs-CALY co-cultures and NETs release was determined after $4 \mathrm{~h}$ of incubation as above described. To evaluate the ROS, autophagy and NF- $\kappa \mathrm{B}$ role in NETs formation in response to C. albicans, PMNs, in NET Medium, were pre-treated with $N$-acetyl cysteine (NAC, $1 \mathrm{mM}$ ), a ROS scavenger, or WT (1 nM), an autophagy suppressor via inhibition of class III PI3K (Blommaart et al., 1997; Remijsen et al., 2011; Yang et al., 2013), or BAY 11-7082 (2.5 $\mu \mathrm{M})$, an irreversible inhibitor of NF- $\mathrm{KB}$ activation, for $30 \mathrm{~min}$ at $37^{\circ} \mathrm{C}$ and $5 \% \mathrm{CO}_{2}$. Then the cells were incubated alone or with pre-opsonized CAH (E:T = 1:2), CALY or CAIY $(\mathrm{E}: \mathrm{T}=1: 2)$. Then NETs formation was determined as above described. Unstimulated cells were used as negative controls. WT and BAY 11-7082 were in DMSO and the final concentration did not have toxic effect $(0,1 \% \mathrm{v} / \mathrm{v})$.

\section{Microscopy Detection of NETs Formation}

To visualize NETs, fluorescence microscopy was performed (Kirchner et al., 2012). Human neutrophils, $5 \times 10^{5} / 500 \mu \mathrm{l}$ in NET medium, settled in a chamber slide (Fisher Scientific, Rouchester, NY, USA), pre-treated or not with DNase-1 $\left(100 \mathrm{U} / \mathrm{ml}\right.$; for $20 \mathrm{~min}$ at $37^{\circ} \mathrm{C}$ and $\left.5 \% \mathrm{CO}_{2}\right)$, were incubated alone or with pre-opsonized CAH, CALY, or CAIY (E:T = 1:2), for $4 \mathrm{~h}$ at $37^{\circ} \mathrm{C}$ with $5 \% \mathrm{CO}_{2}$. After incubation, the cells were fixed with $4 \%$ paraformaldehyde (PFA) for $10 \mathrm{~min}$ at room temperature. Subsequently, the supernatant was removed, and the air-dried chamber slides were rehydrated in PBS-DNase free and stained with SYTOXgreen $(100 \mathrm{nM})$ for $60 \mathrm{~min}$ in the dark at room temperature. After washing three times with PBS-DNase free, the samples were mounted with Pro-Long and analyzed by fluorescent microscope (Leica DMRB).

For staining of neutrophil elastase, after rehydration, with PBS-DNase free, samples were blocked overnight at room temperature with $10 \%$ normal goat serum, $5 \%$ cold water fish gelatin, $1 \%$ BSA and 0,05\% tween-20 diluted in PBS-DNase free. Afterward, cells were washed with PBS-DNase free and incubated with antibody to neutrophil elastase rabbit (H-57; $1: 50)$ for $60 \mathrm{~min}$ at $37^{\circ} \mathrm{C}$. Then, the cells were washed three times with PBS-DNase free, incubated, in the dark, with TR conjugated goat antibody to rabbit IgG (1:100) for $60 \mathrm{~min}$ at $37^{\circ} \mathrm{C}$, washed three times with PBS-DNase free and stained with SYTOXgreen $(100 \mathrm{nM})$ for $60 \mathrm{~min}$ in the dark at room temperature. The microscopical analysis was performed as above described.

\section{Determination of ROS Production}

Total ROS production was measured by chemiluminescent assay. Human neutrophils $\left(4 \times 10^{5} / 200 \mu \mathrm{l}\right)$, pre-treated or not with NAC (1 mM), were incubated, in chemiluminescent medium (CL medium, RPMI-1640 modified without phenol red and sodium hydrogen, Hepes $20 \mathrm{mM}$ ), with CAH, CALY, or CAIY $(\mathrm{E}: \mathrm{T}=1: 2)$, pre-opsonized with $\mathrm{HS}$ at $10 \%$ in RPMI for $30 \mathrm{~min}$ at $37^{\circ} \mathrm{C}$ and extensively washed after opsonization. $0.06 \mathrm{mM}$ luminol was added to each sample and light emission was analyzed every $2 \mathrm{~min}$ for a period of $180 \mathrm{~min}$ by luminometer reader (TECAN Infinite M200). The light emission levels are expressed as RLU (relative light units = luminescence value given by the luminometer). As negative control cells were left in CL medium alone. Quantification of total ROS production was determined by calculation of area under curve (AUC; Ermert et al., 2009).

\section{Western Blotting for LC3B-II and pNF-kB}

Human neutrophil $\left(4 \times 10^{6} / 200 \mu \mathrm{l}\right)$ were incubated, in NET medium, with CAH, CALY, or CAIY (E:T $=1: 2$; pre-opsonized with $\mathrm{HS}$ at $10 \%$ in RPMI for $30 \mathrm{~min}$ at $37^{\circ} \mathrm{C}$ and extensively washed after opsonization) at $37^{\circ} \mathrm{C}$ with $5 \% \mathrm{CO}_{2}$, for $15 \mathrm{~min}$ and $4 \mathrm{~h}$. After incubation the cells were harvested, washed twice with PBS and the pellets were subjected to protein extraction with $20 \mu \mathrm{l}$ of M-PER in presence of protease inhibitors (Sigma-Aldrich) and phosphatase inhibitors (Sigma-Aldrich). Protein concentrations were determined with a bicinchoninic acid (BCA) protein assay reagent kit (Pierce). The lysates (80 $\mu \mathrm{g}$ of each sample) were separated by sodium dodecyl sulfate $12 \%$ polyacrylamide gel electrophoresis (SDS-PAGE), and transferred to a nitrocellulose membrane (Pierce) for $90 \mathrm{~min}$ at $100 \mathrm{~V}$ in a blotting system (Bio-Rad) for Western Blot analysis. Membranes were placed in blocking buffer (3\% no fat dry milk), and incubated overnight at $4^{\circ} \mathrm{C}$ with rabbit polyclonal antibodies to LC3B (D11; 1:1000), to pNF- $\mathrm{B}$ p65 (Ser536; 1:200), or to NF-кB p65 (1:200). Immunoblotting with rabbit polyclonal antibody to actin ( $\mathrm{H} 300 ; 1: 200)$ were used as internal loading controls to ensure equivalent amounts of protein in each lane. Detection was achieved using appropriate HRP-linked secondary antibodies, followed by Immun-Star ${ }^{\text {TM }}$ HRP chemiluminescent kit (Bio-Rad). Immunoreactive bands were visualized and quantified by Chemidoc Instruments (Bio-Rad).

\section{Flow-Cytometry Analysis of pNF-kB}

Fresh human neutrophils $\left(1 \times 10^{6} / 500 \mu \mathrm{l}\right)$ were incubated, in NET Medium, with CAH, CALY, or CAIY (E:T $=1: 2$; preopsonized with $\mathrm{HS}$ at $10 \%$ in RPMI for $30 \mathrm{~min}$ at $37^{\circ} \mathrm{C}$ ), for $15 \mathrm{~min}$ and $4 \mathrm{~h}$ at $37^{\circ} \mathrm{C}$ and $5 \% \mathrm{CO}_{2}$. Then the cells were collected, washed with PBS, fixed with $1.5 \%$ PFA for $10 \mathrm{~min}$ at room temperature, washed twice with $\mathrm{PBS}$ and permeabilized with Methanol for $10 \mathrm{~min}$ at $4^{\circ} \mathrm{C}$. After permeabilization the cells were washed twice with $\mathrm{PBS}$ and incubated with rabbit monoclonal antibody to pNF- $\kappa \mathrm{B}$ p65 (PE conjugated; 1:50) or with rabbit monoclonal antibody isotype-matched control (PEconjugated; (1:50) for $30 \mathrm{~min}$ at $4^{\circ} \mathrm{C}$. Cells were washed twice 
with PBS and 5000 events were analyzed by flow cytometry using FACS Calibur and Cell Quest Pro software (BD Biosciences, San Diego, CA, USA). Unstimulated neutrophils were used as control.

\section{Killing Experiments}

Fresh human neutrophils were suspended in NET medium at concentration of $10^{5} / 100 \mu \mathrm{l}$ in a 96 wells plate, pre-treated or not with DNase-1 $(100 \mathrm{U} / \mathrm{ml})$, to degrade extracellular DNA, or Cytochalasine D (cytD; $10 \mu \mathrm{g} / \mathrm{ml})$, to block phagocytosis of fungi by neutrophils, for $20 \mathrm{~min}$ at $37^{\circ} \mathrm{C}$ and $5 \% \mathrm{CO}_{2}$ (Urban et al., 2006), and incubated with C. albicans gLUC59 hyphae or C. albicans gLUC59 yeast, (pre-opsonized with HS at $10 \%$ in RPMI for $30 \mathrm{~min}$ at $37^{\circ} \mathrm{C}$ and extensively washed after opsonization), at an $\mathrm{E}: \mathrm{T}=10: 1$, at $37^{\circ} \mathrm{C}$ and $5 \% \mathrm{CO}_{2}$ for $2 \mathrm{~h}$ (Enjalbert et al., 2009). Control cultures consisted of C. albicans gLUC59 hyphae or C. albicans gLUC59 yeast incubated without effector cells. After incubation $1 \mu \mathrm{l}$ of coelenterazine $(1 \mathrm{mg} / \mathrm{ml}$ in 1:10 methanol: $\mathrm{H}_{2} \mathrm{O}$ ) was added to each well. The plate was briefly shaken and total bioluminescence emission was measured immediately and quantified with TECAN Infinite M200 using $1 \mathrm{~s}$ counting time. The light emission levels are expressed as RLU (relative light units = luminescence value given by the luminometer). Killing activity (Vecchiarelli et al., 1994; Enjalbert et al., 2009) vs. C. albicans was expressed as the percentage of RLU inhibition, according to the following formula: \% killing activity $=100-$ (RLU from the experimental group/RLU from control cultures) $\times 100$. NET-mediated killing (Young et al., $2011)$ vs. C. albicans was determined by subtracting the extent of killing in the presence of DNAse-1 from total killing and expressed as the percentage of total killing reduction.

\section{Statistical Analysis}

Data are reported as the mean \pm standard error of the mean (SEM) from 3 to 7 separate experiments. Statistical analysis, was performed by using Student's $t$-test. A value of $P<0.05$ was considered significant.

\section{RESULTS}

\section{Induction of NETs Formation by C. albicans Morphotypes}

To determine extracellular DNA released from human neutrophils (PMNs) stimulated with C. albicans morphotypes, PMNs were incubated with hyphal (CAH) or live yeast (CALY) cells for different time periods ( $15 \mathrm{~min}$ and $4 \mathrm{~h}$ ) at $37^{\circ} \mathrm{C}$ and $5 \%$ $\mathrm{CO}_{2}$ and at an effector to target ratio 1:2, according to previous report (Ermert et al., 2009). In our experimental conditions C. albicans yeast does not undergo filamentation in $4 \mathrm{~h}$ of incubation, according with what previously demonstrated by Ermert et al. (2013).

Extracellular DNA was quantified by using SYTOXgreen, a molecule that is fluorescent when it intercalates into strand of DNA, but does not enter live cells. The results (Figure 1A) show a significant early release of extracellular DNA from PMNs stimulated with both morphotypes. In particular, after $15 \mathrm{~min}$ of incubation, hyphal form induced significantly higher release of extracellular DNA in comparison to yeast form $(P<0.05)$ ); after $4 \mathrm{~h}$ of incubation, $\mathrm{CAH}$ induced a progressive increase of extracellular DNA, whereas NET was negligible in response to CALY. For a better understanding the mechanism of timedependent NET release, in response to live C. albicans yeast, we included, in our experimental system, heat inactivated yeast (CAIY).

To visualize NETs formation, neutrophils were co-incubated or not (NS) with CAH, CALY or CAIY for $4 \mathrm{~h}$ and stained with SYTOXgreen alone, with SYTOXgreen in the presence of $\mathrm{mAb}$ to Elastase, or DNase-1 $(100 \mathrm{U} / \mathrm{ml})$, that is able to degrade NET. As shown in Figure 1B, CAH induced large amounts of extracellular DNA release and neutrophils show delobulated nuclei. Conversely, the extracellular DNA was not observed after stimulation with CALY and neutrophils appear intact bearing lobulated nuclei. Surprisingly, the inactivated yeast-form (CAIY) is able to induce DNA release. To determine whether the low amount or the absence of extracellular DNA, released in response to live yeast, could be due to the metabolic activity of these cells, supernatant from co-culture of PMNs plus live C. albicans yeast (CALY) were harvested, after $15 \mathrm{~min}$ of incubation, and added to co-culture of PMNs plus heat inactivated C. albicans yeast (CAIY). After $4 \mathrm{~h}$ of incubation, extracellular DNA was quantified, by using SYTOXgreen; the results show that the addition of the supernatant caused a reduction of extracellular DNA release in response to CAIY of about $30 \%$.

The capacity of NET induction was also tested by using heat inactivated hyphae and the results showed that they released NETs efficiently like live hyphae as previously published (Branzk et al., 2014).

\section{Inhibition of ROS Production Results in a Reduction of NETs Formation}

Given that ROS production may participate in NET induction (Ermert et al., 2009), real time monitoring of total ROS was performed by using luminol enhanced chemiluminescence. The PMNs were pre-treated or not with $N$-acetyl-L-cysteine (NAC), a well-known antioxidant, and, then, CAH, CALY, or CAIY (E/T: 1/2) were added for $180 \mathrm{~min}$. The results (Figure 2A) show that hyphae as well as, live or inactivated, yeast cells stimulated ROS production. The quantity of ROS released varied depending on the morphotype used. At any rate, ROS production, by each stimulator, was drastically reduced by NAC.

To determine if the inhibition of ROS production affected NETs release, in our experimental conditions, PMNs, pre-treated or not with NAC (1 mM), were incubated with CAH, CALY, or CAIY (E/T:1/2) for $15 \mathrm{~min}$ and $4 \mathrm{~h}$ at $37^{\circ} \mathrm{C}$ and $5 \% \mathrm{CO}_{2}$. The results (Figure $2 \mathrm{~B}$ ) show that, after $15 \mathrm{~min}$ of incubation, NAC pre-treatment did not affect NET formation in response to $\mathrm{CAH}$ or CAIY, while caused significant inhibition in response to CALY. In addition, at this time, CAIY induced a significant early NETs release. By prolonging the incubation, until $4 \mathrm{~h}$, a marked involvement of ROS in NET release was evidenced after 
A

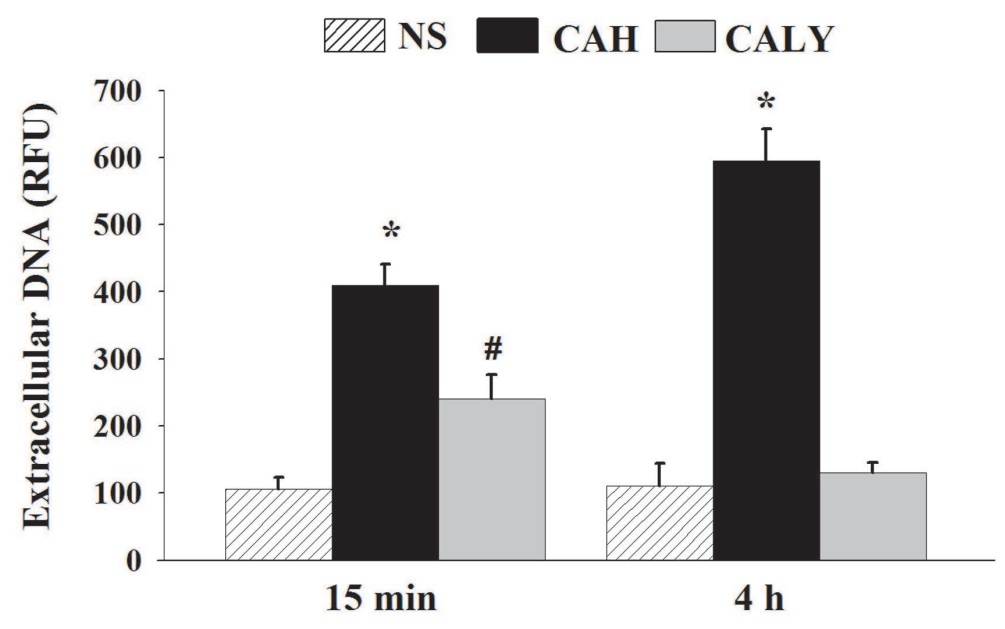

B
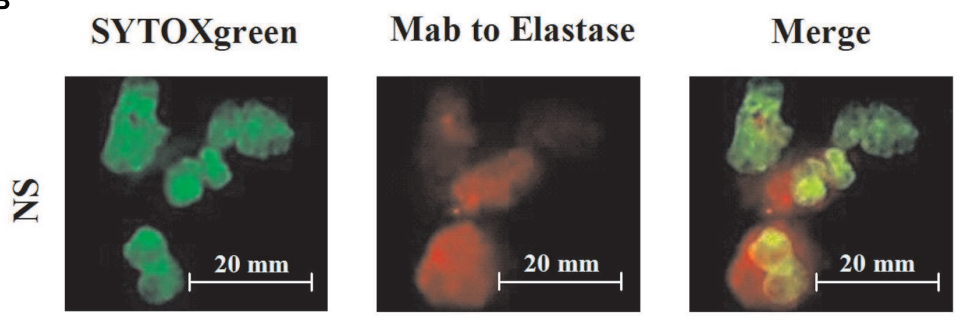

SYTOXgreen +

DNase-1
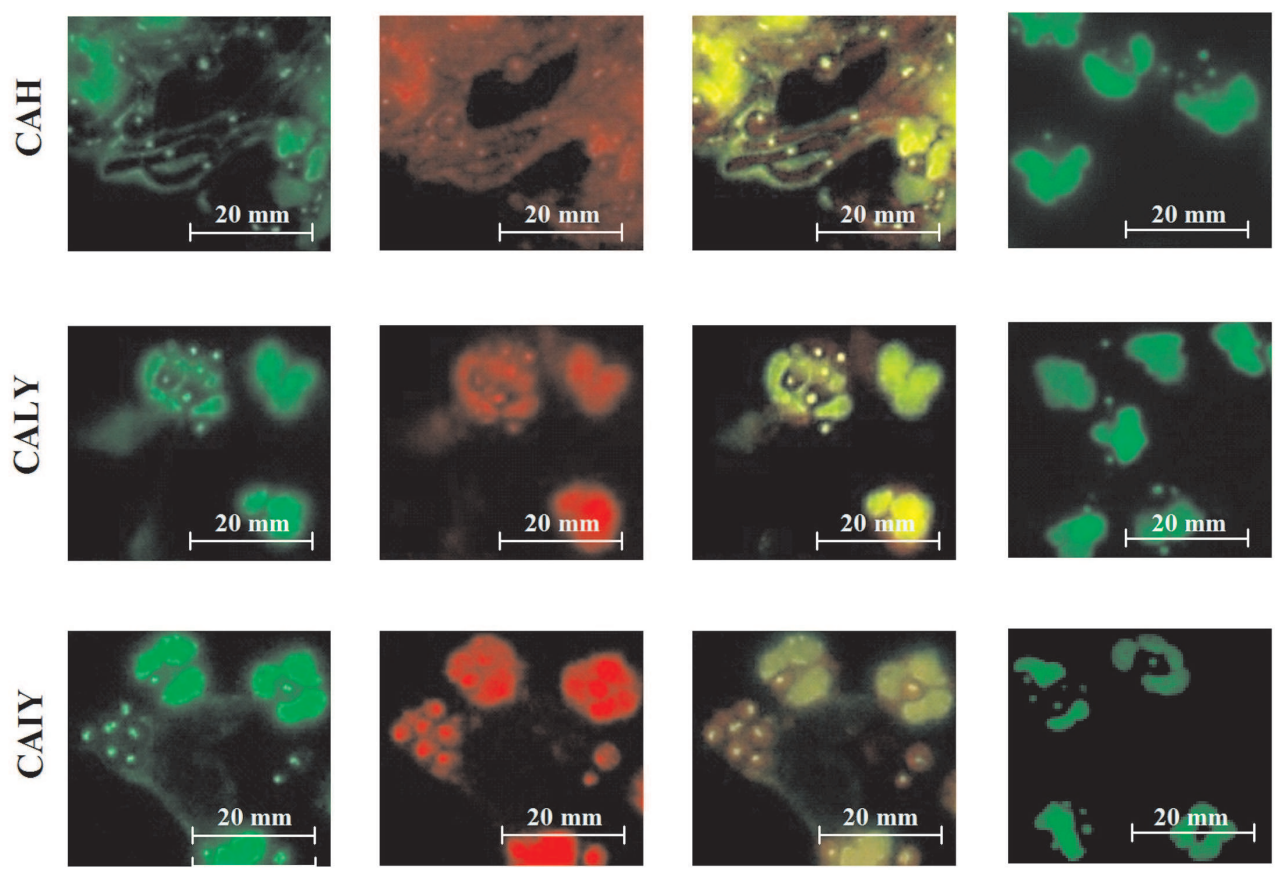

FIGURE 1 | NETs formation induced by C. albicans. (A) Extracellular DNA released, in response to PMNs not stimulated (NS) or incubated with C. albicans hyphae (CAH) or live yeast (CALY), for 15 min or $4 \mathrm{~h}$ at $37^{\circ} \mathrm{C}$ and $5 \%$ of $\mathrm{CO}_{2}$, was determined using SYTOXgreen probe, as described in Section "Materials and Methods." Bars are the mean \pm SEM of $n=7$ experiments with similar results. ${ }^{*} P<0.05$ PMNs + CAH vs. PMNs NS; ${ }^{~} P<0.05$ PMNs + CALY vs. PMN NS. (B) NET components (green: extracellular DNA; red: neutrophil elastase) were visualized by fluorescence microscopy after $4 \mathrm{~h}$ of PMNs incubation without stimuli (NS) or with C. albicans hyphae (CAH), live yeast (CALY), or heat inactivated yeast (CAIY). In the presence of DNAse-1 (100 U/ml), NET was completely degraded. Microphotography from a representative experiment $(n=3)$ are shown. 
A
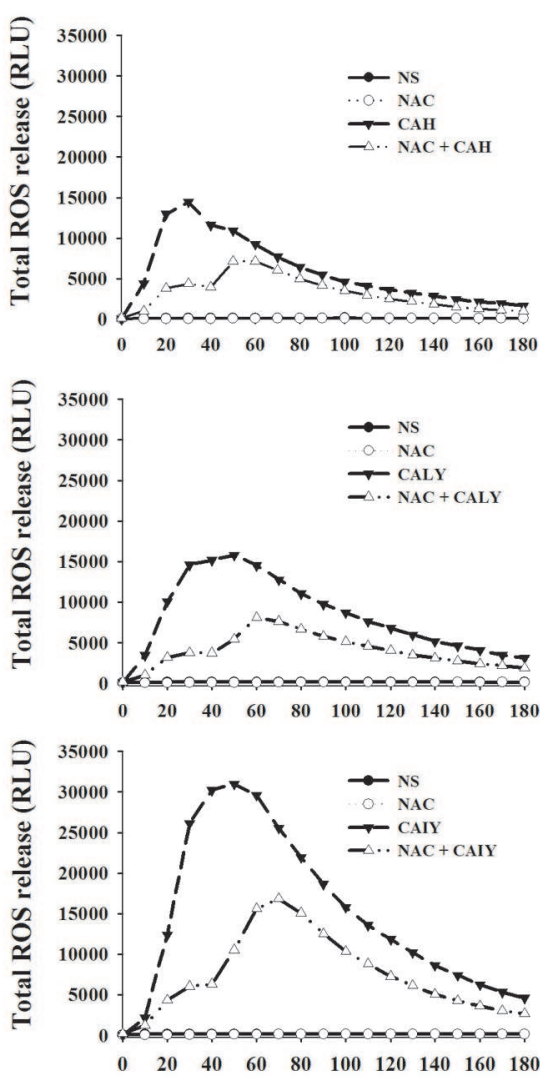

Time (min)
B
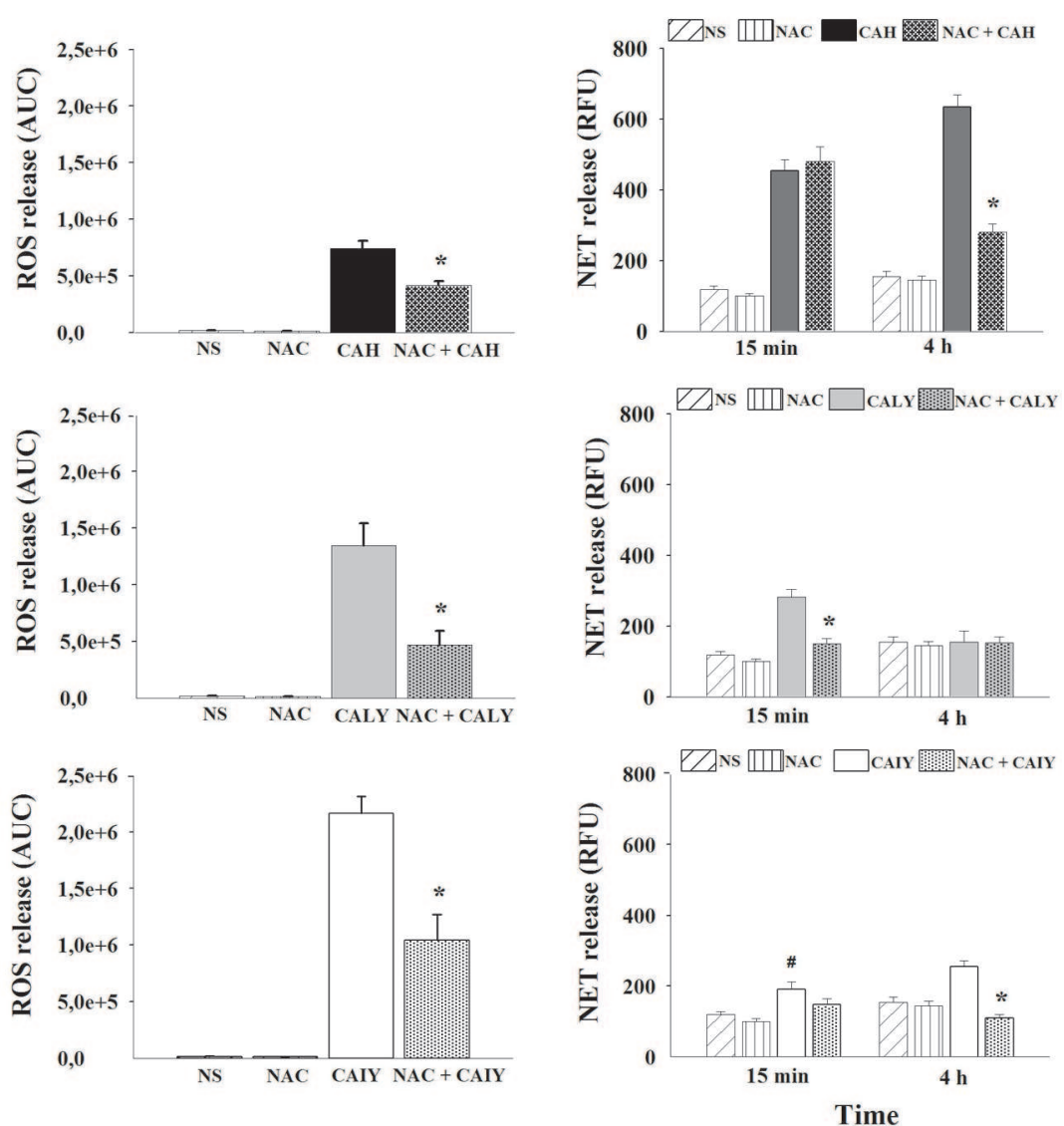

FIGURE 2 | Inhibition of ROS production causes a reduction of NETs formation C. albicans induced. PMNs, pre-treated or not with N-acetyl L Cysteine (NAC, 1mM), were incubated without stimuli (NS) or with C. albicans hyphae (CAH), live yeast (CALY) or heat inactivated yeast (CAIY), and ROS production (A) and NETs formation (B) were determined as described in Section "Materials and Methods." (A) The lines represent the kinetic of ROS release. The bars represent the total amounts of produced ROS obtained by analyzing the area under the curve (AUC). Lines are representatives of $n=5$ experiments with similar results. Bars are the mean \pm SEM of $n=5$ experiments with similar results. ${ }^{*} P<0.05$ PMNs NAC pre-treated vs. PMNs not pre-treated. (B) NET formation in response to CAH, to CALY or to CAIY after 15 min and 4 h of incubation. Bars are the mean \pm SEM of $n=7$ experiments with similar results. ${ }^{*} P<0.05$ PMNs pre-treated with $\mathrm{NAC}+\mathrm{CAH}$ or CALY vs. PMNs not pre-treated; ${ }^{\#} P<0.05$ PMNs + CAIY vs. PMNs NS.

stimulation with CAH and CAIY, as evidenced by significant NAC-mediated inhibition of NETs formation (Figure 2B).

\section{Inhibition of Autophagy Results in a Reduction of NETs Formation}

It has been reported that autophagy pathway may be involved in NET induction (Remijsen et al., 2011), thus we evaluated whether, in our experimental conditions, the autophagy was induced by CAH, CALY, or CAIY. To this end the LC3B-II expression, marker of autophagy (Barth et al., 2010), was evaluated. PMNs, pre-treated or not with WT (1 nM), well known autophagy suppressor (Yang et al., 2013) via persistent inhibition of Class III PI3 kinases (Barth et al., 2010; Wu et al., 2010; Yang et al., 2013), were stimulated with CAH, CALY, or CAIY (E/T: 1/2), for $15 \mathrm{~min}$ and $4 \mathrm{~h}$ at $37^{\circ} \mathrm{C}$ and $5 \% \mathrm{CO}_{2}$. Preliminary experiments showed that the optimal inhibition of LC3B-II expression was obtained at a dose of $1 \mathrm{nM}$ of WT.
The results reported in Figure 3A, show a significant increase of LC3B-II expression after $15 \mathrm{~min}$, in response to CAH, CALY as well as to CAIY and after $4 \mathrm{~h}$ in response to CAH and CAIY. The treatment with WT suppressed LC3B-II expression in all the cases in which activation was observed. We, next, examined the possible involvement of autophagy in NET release. To this end, PMNs, pre-treated or not with WT, were stimulated with CAH, CALY, or CAIY (E/T: 1/2) for $15 \mathrm{~min}$ and $4 \mathrm{~h}$. The results (Figure 3B) show that WT pre-treatment produced a significant reduction of NETs formation in response to CAH, CALY, and CAIY after $15 \mathrm{~min}$ and in response to CAH or CAIY after $4 \mathrm{~h}$.

\section{Inhibition of NF-кB Activation Results in a Reduction of NETs Release}

It has been reported that the activation of NF- $\kappa \mathrm{B}$ p 65 subunit is a relevant signaling pathway to the generation of DNA traps (Lapponi et al., 2013). Therefore, experiments were performed 
A
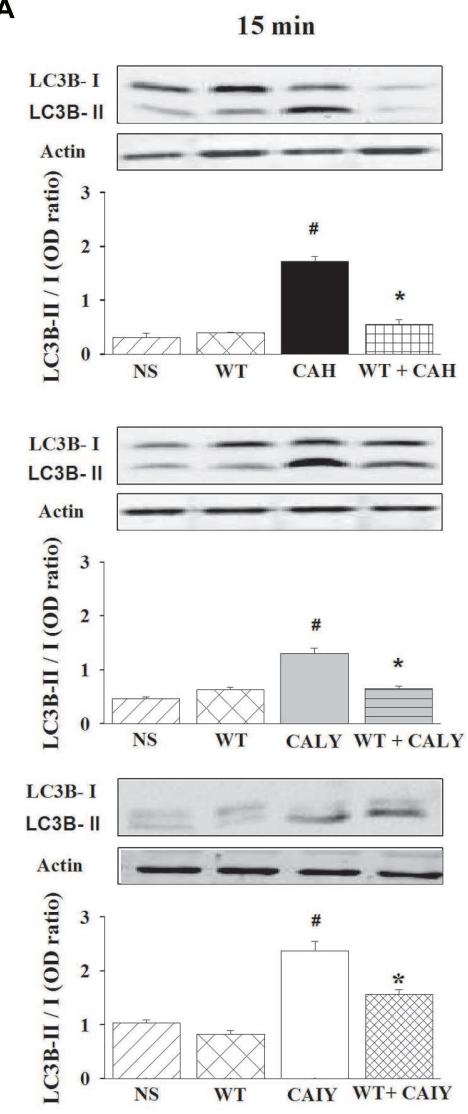

4h
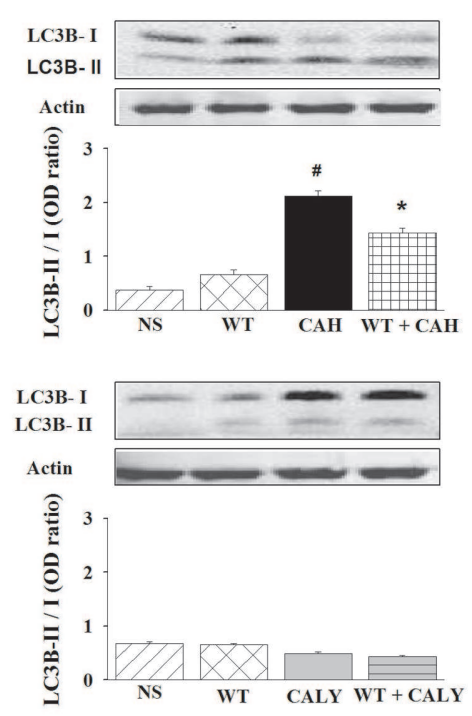

LC3B- I

LC3B- II
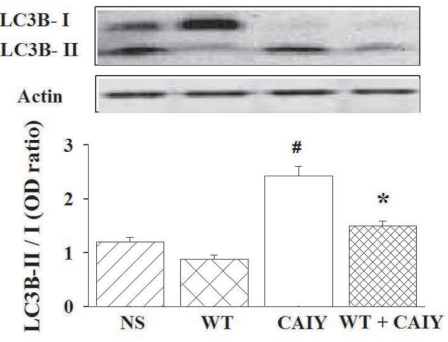

B

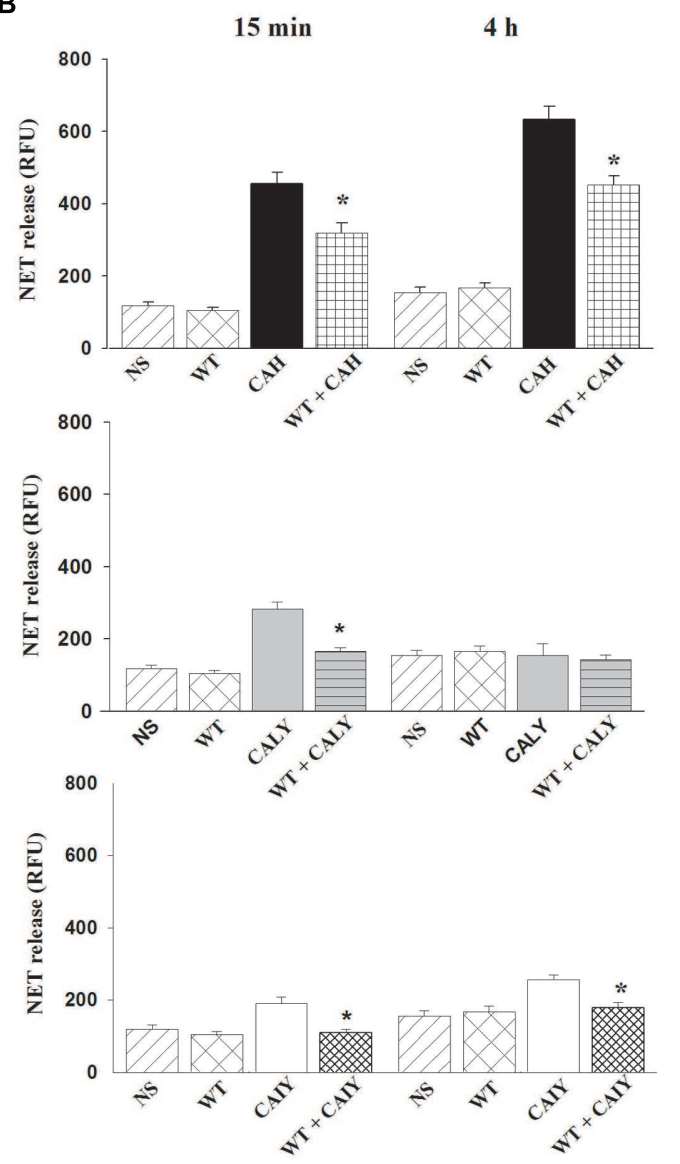

FIGURE 3 | Inhibition of autophagy causes a reduction of NETs release C. albicans mediated. PMNs, pre-treated or not with WT (1 nM), were incubated without stimuli (NS) or with C. albicans hyphae (CAH), live yeast (CALY) or heat inactivated yeast (CAIY) and Western Blotting experiments for LC3B-II expression (A) and NET release determination (B) were performed as described in Section "Materials and Methods." (A) LC3B-II expression in response to CAH, to CALY or to CAIY after $15 \mathrm{~min}$ and $4 \mathrm{~h}$ of incubation. Actin was used as loading control. Optical density of reactive bands was measured and LC3B-II/LC3B-I ratio was evaluated. PMNs treated with DMSO alone were also run in parallel and the results were similar to those obtained in absence of WT. Blots and bars are representative of experiments $(n=3)$ with similar results. ${ }^{\#} P<0.05$ PMNs + CAH or CALY or CAIY vs. PMNs NS. (B) NETs formation in response to CAH, to CALY or to CAlY after $15 \mathrm{~min}$ and $4 \mathrm{~h}$ of incubation. PMNs treated with DMSO alone were also analyzed in parallel and the results were similar to those obtained in absence of WT. Bars are the mean \pm SEM of $n=5$ experiments with similar results. ${ }^{*} P<0.05$ PMNs pre-treated with $W T+$ CAH or CALY or CAlY vs. PMN not pre-treated.

to analyze the possible involvement of NF-кB activation in NET release. First of all, we evaluated the activation of NF- $\kappa \mathrm{B}$ in response to CAH, CALY, or CAIY. Western blotting analysis (Figure 4A) shows that $C$. albicans hyphae triggered a strong $\mathrm{NF}-\kappa \mathrm{B}$ activation after $15 \mathrm{~min}$ as well as after $4 \mathrm{~h}$ of incubation, while the C. albicans yeast, live and inactivated, stimulated NF- $\kappa$ B phosphorylation, only, after $4 \mathrm{~h}$ of co-culture with PMNs.

To assess a functional role for NF- $\kappa \mathrm{B}$ in C. albicans-mediated NET release (Figure 4B), neutrophils were pre-treated or not with a NF- $\kappa$ B inhibitor $\left(2.5 \mu \mathrm{M}\right.$ ) for $30 \mathrm{~min}$ at $37^{\circ} \mathrm{C}$ (Lapponi et al., 2013) and, then, stimulated with CAH, CALY, or CAIY (E/T: $1 / 2$ ) for $15 \mathrm{~min}$ and $4 \mathrm{~h}$. The results show a significant inhibition of NET formation in response to hyphal form at both times. Regarding C. albicans yeast, pre-treatment with NF- $\kappa \mathrm{B}$ inhibitor produced a down-regulation of NET release, only, in response to inactivated yeast in a $4 \mathrm{~h}$ of incubation. Preliminary experiments were performed using various doses of
NF-кB inhibitor (BAY 11-7082; 1.25-2.5-5-10 $\mu \mathrm{M}$ ). The results showed that the optimal dose to reduce NETs release in response to $\mathrm{CAH}$ or CAIY was $2.5 \mu \mathrm{M}$ according to Lapponi et al. (2013), who consistently demonstrated that NF-кB inhibitor is able to inhibit both pNF-кB and NET induction. Indeed, by using cytofluorimetric analysis, we, also, demonstrated that the $\mathrm{NF}-\kappa \mathrm{B}$ inhibitor pre-treatment produced a down-regulation of pNF- $\mathrm{B}$ expression in each case in which activation was observed (Figure 5).

\section{Role of ROS, Autophagy, and NF- $\kappa$ B in NETs Formation Induced by C. albicans Morphotypes}

To better understand the role of ROS, autophagy, and NF- $\kappa \mathrm{B}$ in NET generation, we determined the percentages of NETs reduction after treatment with NAC or WT or NF- $\mathrm{NB}$ inhibitor. 
A
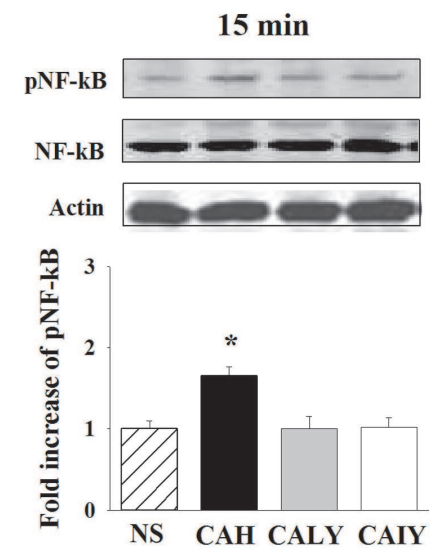

B
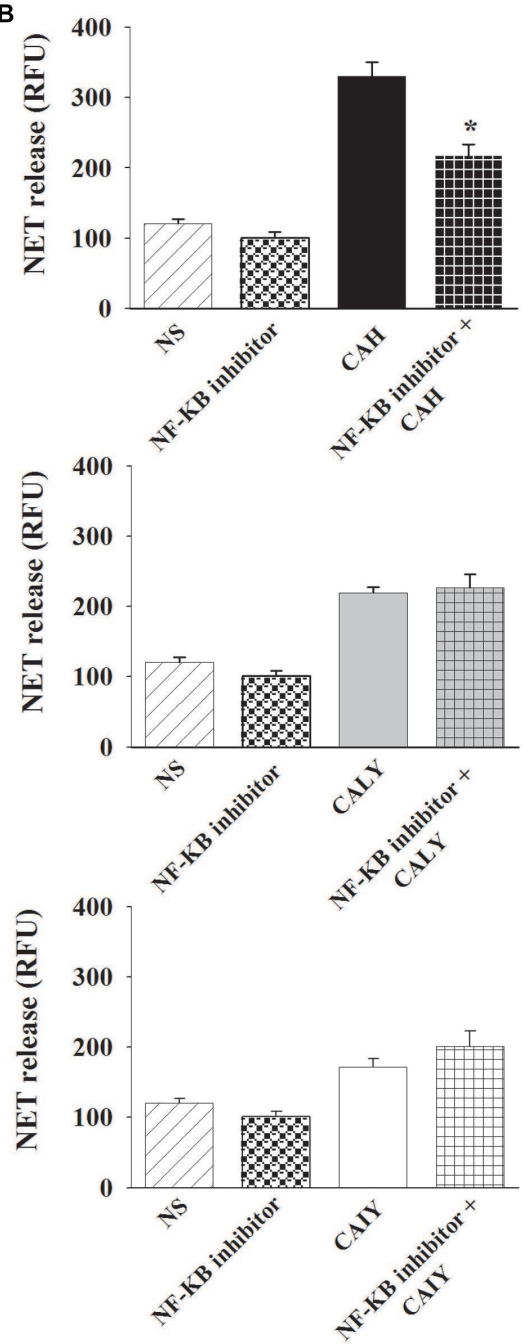

$4 h$
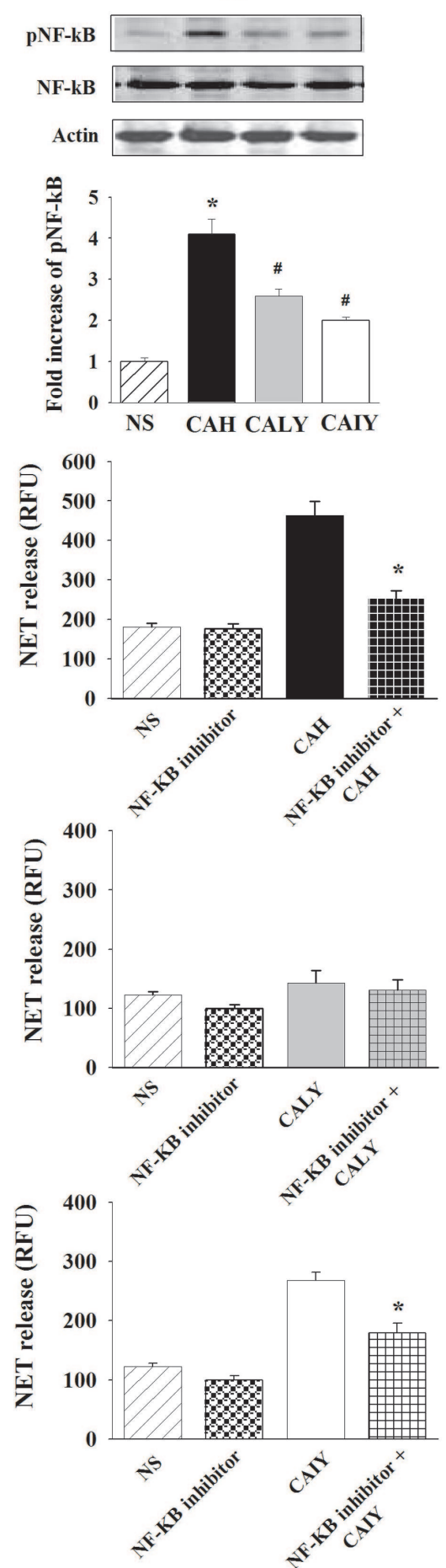

FIGURE 4 | Inhibition of NF-KB activation causes a reduction of NETs release $\boldsymbol{C}$. albicans induced. PMNs, were incubated without stimuli (NS) or with C. albicans hyphae (CAH), live yeast (CALY) or heat inactivated yeast (CAIY) and (A) Western Blotting analysis for pNF-KB and (B) NET release determination were performed as described in Section "Materials and Methods." (A) NF-kB activation in response to CAH, to CALY or to CAlY after 15 min and $4 \mathrm{~h}$ of incubation. Optical density of reactive bands was measured and normalized by the NF-kB density in the same line. pNF-kB was quantified relative to PMNs NS. Actin was used as loading control. Blots are representative of experiments $(n=3)$ with similar results. Bars are the mean \pm SEM of experiments $(n=3)$ with similar results. ${ }^{*} P<0.05$ PMNs + CAH vs. PMN NS; ${ }^{P} P<0.05$ PMNs + CALY or CAIY vs. PMN NS. (B) NET release determination in PMNs stimulated as above described, but pre-treated with NF-kB inhibitor $(2.5 \mu \mathrm{M})$. The bars are the mean \pm SEM of $n=5$ experiments with similar results. ${ }^{*} P<0.05$ PMNs pre-treated with NF-kB inhibitor + CAH or CAIY vs. PMNs stimulated with CAH or CAIY. 


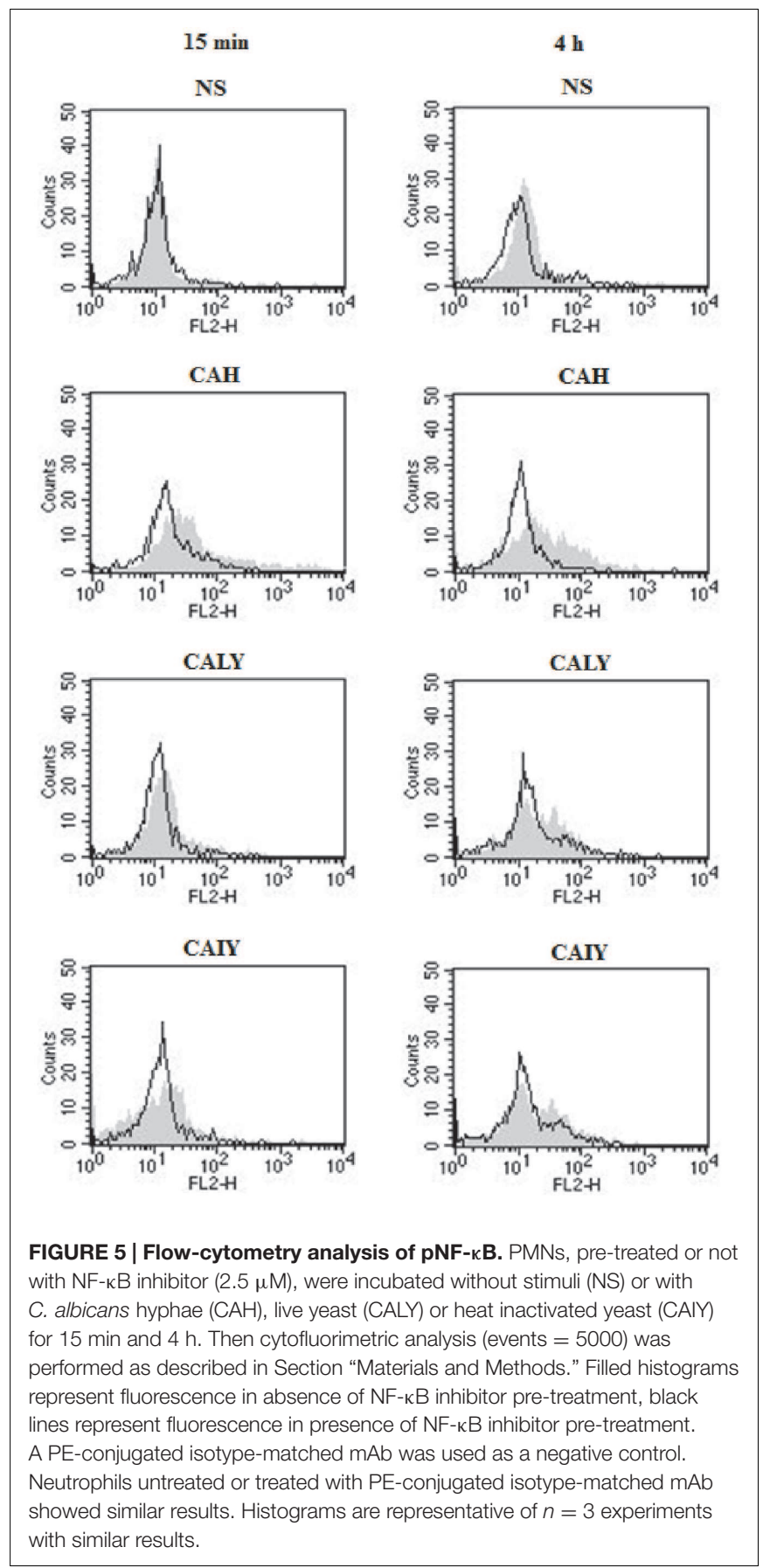

The Figure 6A shows that, ROS production is involved, in the early NETs release $(15 \mathrm{~min})$ induced by live $C$. albicans yeast. Furthermore ROS is, also, involved in NETs released, by C. albicans hyphae and by inactivated C. albicans yeast in a 4 h of incubation.

The autophagy (Figure 6B), is implicated in rapid NET release stimulated by CAH, CALY, and CAIY and continues to be involved, until $4 \mathrm{~h}$ of incubation, in response to by $\mathrm{CAH}$ and CAIY. Regarding the role of NF- $\kappa$ B (Figure 6C) the results show that it is involved only in rapid NET formation stimulated by
C. albicans hyphal form. By prolonging the incubation until $4 \mathrm{~h}$ NF- $\kappa \mathrm{B}$ appears to be involved in NET induced by CAH and CAIY.

\section{NETs-Mediated Killing of C. albicans Hyphae}

Finally the capacity of NETs to kill C. albicans hyphal and yeast forms, was explored. The killing was evaluated in the absence (total killing: intracellular + extracellular killing) or in the presence of DNase-1 $(100 \mathrm{U} / \mathrm{ml})$ to degrade extracellular DNA (to assess extracellular killing without NET-mediated killing), or of Cythocalasin D, (cyt D) to inhibit phagocytosis (to assess extracellular killing). The results show that C. albicans hyphal form was killed by PMNs, essentially by extracellular mechanisms (Figure 7A). Indeed DNase produced a strong inhibition of killing activity, while cytD did not affect killing. The analysis of live C. albicans yeast form killing by PMNs showed that yeast cells were quite entirely killed by intracellular mechanisms. Indeed DNAse did not inhibit the process, while the inhibition of phagocytosis resulted in almost complete inhibition of candidacidal activity (Figure 7B). In addition (Figure 7C) NET activity appears to be inconsistent in PMN killing of yeast form.

\section{DISCUSSION}

Neutrophils are immune cells that, freely, circulate in blood vessel and are considered to be crucials in the defense against infectious diseases. Invasive fungal infections, including candidiasis, represent a serious problem in neutropenic individuals (Horn et al., 2010), moreover the interaction of PMNs with C. albicans is a complex issue that has not been fully elucidated. While a positive role of PMN in systemic candidiasis is ascertained, a massive neutrophil recruitment is considered responsible of pathological inflammation during vaginal candidiasis (Van't Wout et al., 1988).

Neutrophil extracellular traps is included among the mechanisms used by neutrophils to control microbial infections (Brinkmann et al., 2004), and it is able to degrade some microbial virulence factors and kill Gram-positive and Gram-negative bacteria (Matoszka et al., 2012).

In this study, we demonstrate that $C$. albicans hyphae and live yeast induce NETs release using autophagy and ROS with a different kinetics and participation of these two effector mechanisms. In addition, we here report that NETs release, in response to C. albicans hyphae, is regulated via NF- $\kappa \mathrm{B}$ activation and is strongly involved in hyphal destruction.

Autophagy is a biological process of lysosome-mediated intracellular degradation enabling the routine turnover of proteins and organelles. It is considered a host cell effector mechanism to protect against pathogen invasion (Diacovich and Gorvel, 2010). Study by Casadevall's group, showed that macrophage autophagy is important in immunity against $C$. albicans (Nicola et al., 2012). It is now known that NET formation could be dependent on autophagy for the unwinding and extrusion of DNA (Remijsen et al., 2011; Boone et al., 2015), however, the involvement of autophagy in NET formation 


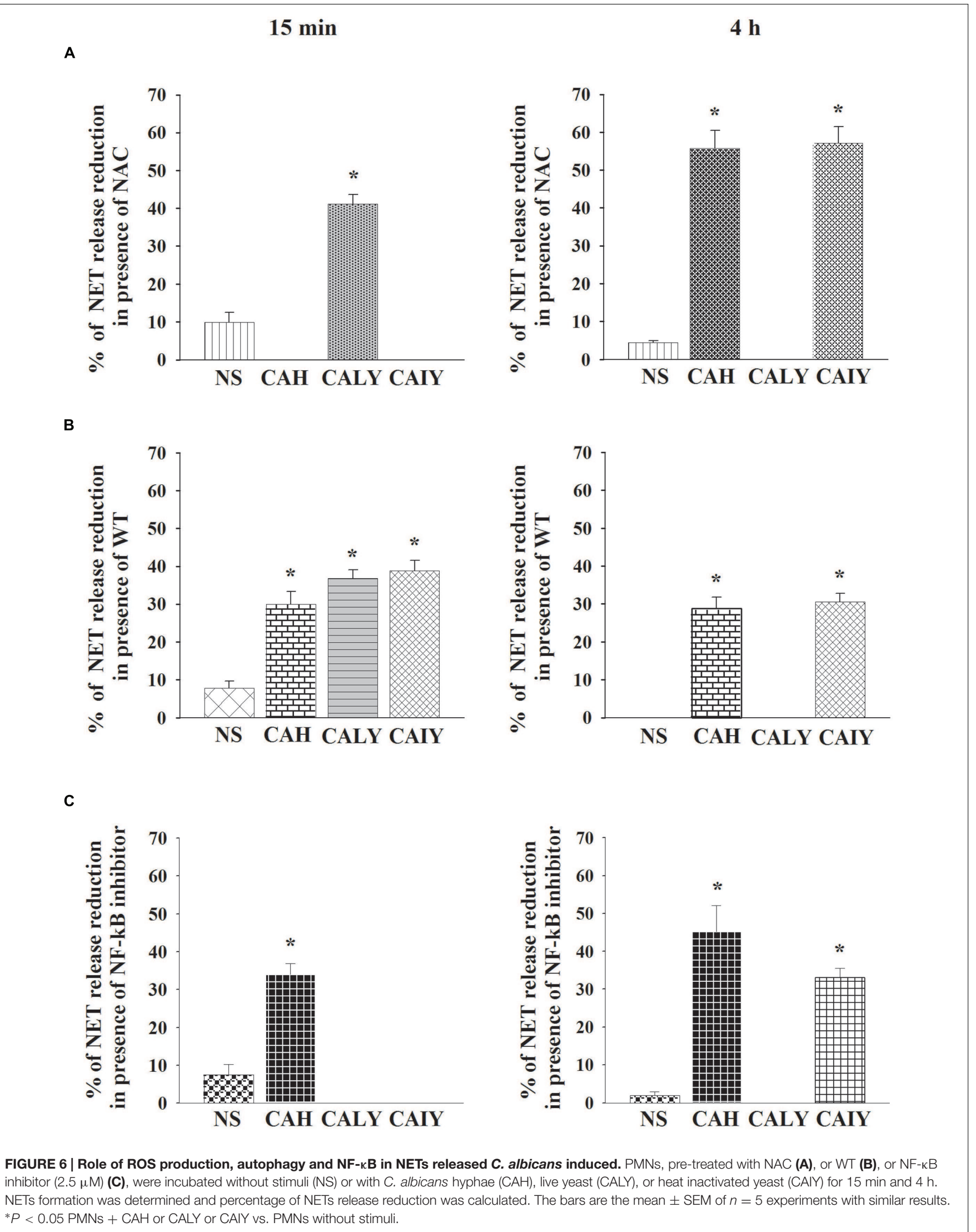




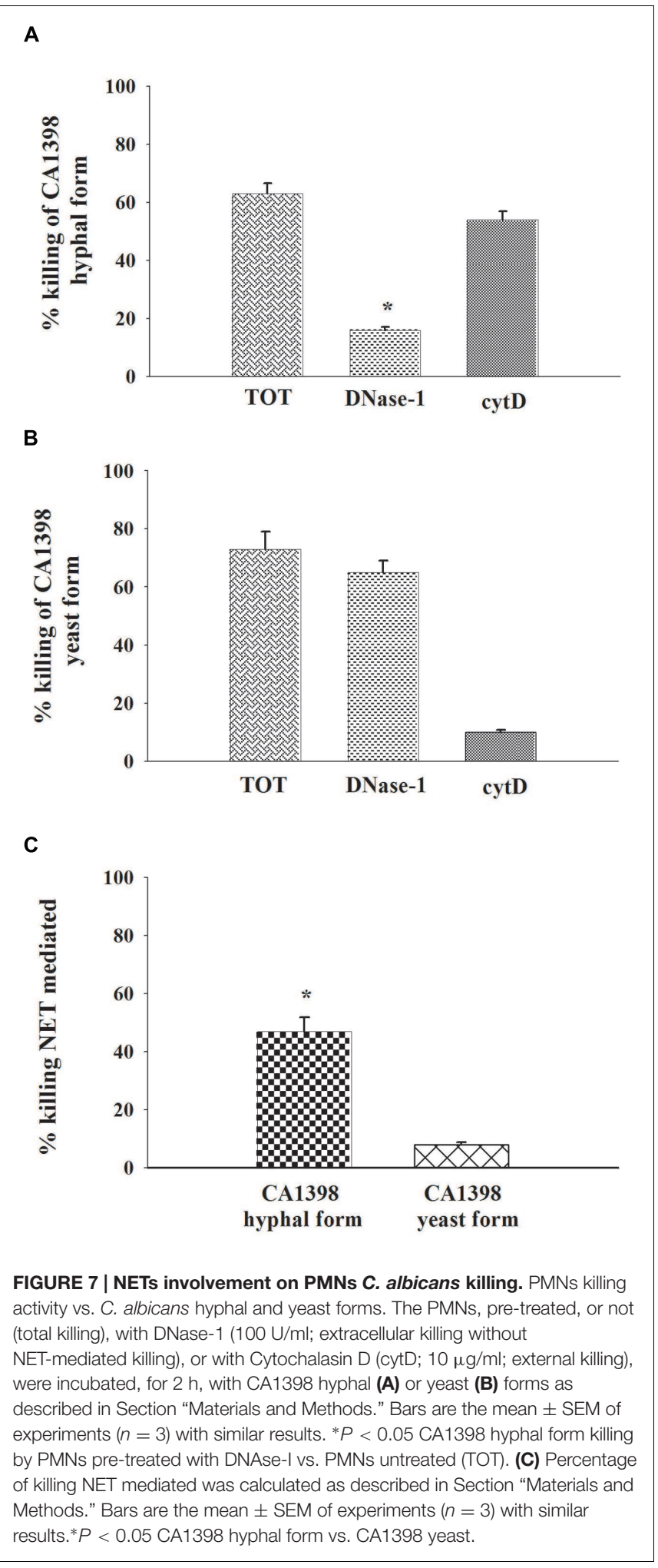

during bacterial or fungal infection has not been elucidated. In this paper, we provide new evidence about the relationship between autophagy and NETs release in response to C. albicans. In particular autophagy plays an important role in triggering a rapid NETs induction in response to both morphotypes of C. albicans. Of note the involvement of autophagy was observed in all NETs inducing conditions in response to each morphotype. Moreover, the observation that autophagy, but not ROS, is involved in rapid NET release in response to hyphal form, is in agreement with a recent report (Byrd et al., 2013). Indeed, in this study, we demonstrate an early expression of LC3b, an autophagy marker, and this is consistent with recent data showing the presence of early and immature autophagic vacuoles in neutrophils stimulated with hyphae (Remijsen et al., 2011).

By prolonging the incubation time, both autophagy and ROS production appear to play a role in NETs release induced by hyphal cells. Overall, our findings reveal the implication of autophagy as a novel aspect of NETs release induced by Candida morphotypes.

Another novel observation from this study is that live C. albicans yeast cells are able to induce a rapid NET generation and that this process is dependent from both autophagy and ROS production.

Previous data (Branzk et al., 2014) showed the absence of NET formation in response to C. albicans yeast after $4 \mathrm{~h}$ of incubation. In this study, we confirmed the inability of C. albicans live yeast to induce NET in a $4 \mathrm{~h}$ of incubation, however, in a very early phase (within $15 \mathrm{~min}$ ) NET formation was observed. Of note, differently from live yeast, inactivated yeast, was able to induce appreciable levels of NET release within $4 \mathrm{~h}$. One possible explanation is that metabolic products released by live yeast, during the contact with neutrophils, could inhibit NET formation. This is supported by the observation that supernatant of live C. albicans co-cultured with neutrophils inhibits NET formation.

It has been reported that an inflammatory components is a key factor for NET release including the activation of transcription factor NF- $\mathrm{KB}$ (Lapponi et al., 2013). Furthermore NF- $\mathrm{KB}$ activation has been involved in neutrophil interaction with C. albicans (Giraldo et al., 2010). Indeed, NF-kB activation is observed in neutrophils treated with all fungal cells tested, including the inactivated fungal cells for both at $15 \mathrm{~min}$ and $4 \mathrm{~h}$ of stimulation. In this study, we demonstrate, for the first time, that the involvement of NF- $\kappa \mathrm{B}$ activation, in NETs release, occurs in response to hyphal cells form consistently at $15 \mathrm{~min}$ and $4 \mathrm{~h}$ and in response to live and inactivated cells, only, after $4 \mathrm{~h}$ of incubation. A scheme of the principal mechanism involved in C. albicans NET-induced is reported in Figure 8.

Neutrophil extracellular traps is suggested as a mechanism to capture and kill Candida hyphae and yeast (Urban et al., 2006). In our experimental system, only a low percentage of CALY was killed by NETs, conversely NETs showed a remarkable killing activity toward CAH. Indeed, accordingly to the capacity of neutrophils to discriminate between yeasts and filaments of C. albicans, the study from Wozniok et al. (2008) reports that human neutrophils are differently activated in response to distinct C. albicans morphotypes. The filamentous form is able to induce ERK signaling that promotes motility of neutrophils and killing of C. albicans filaments. Conversely C. albicans yeast is unable to induce ERK and killing via motility (Wozniok et al., 2008). Given that only a negligible 


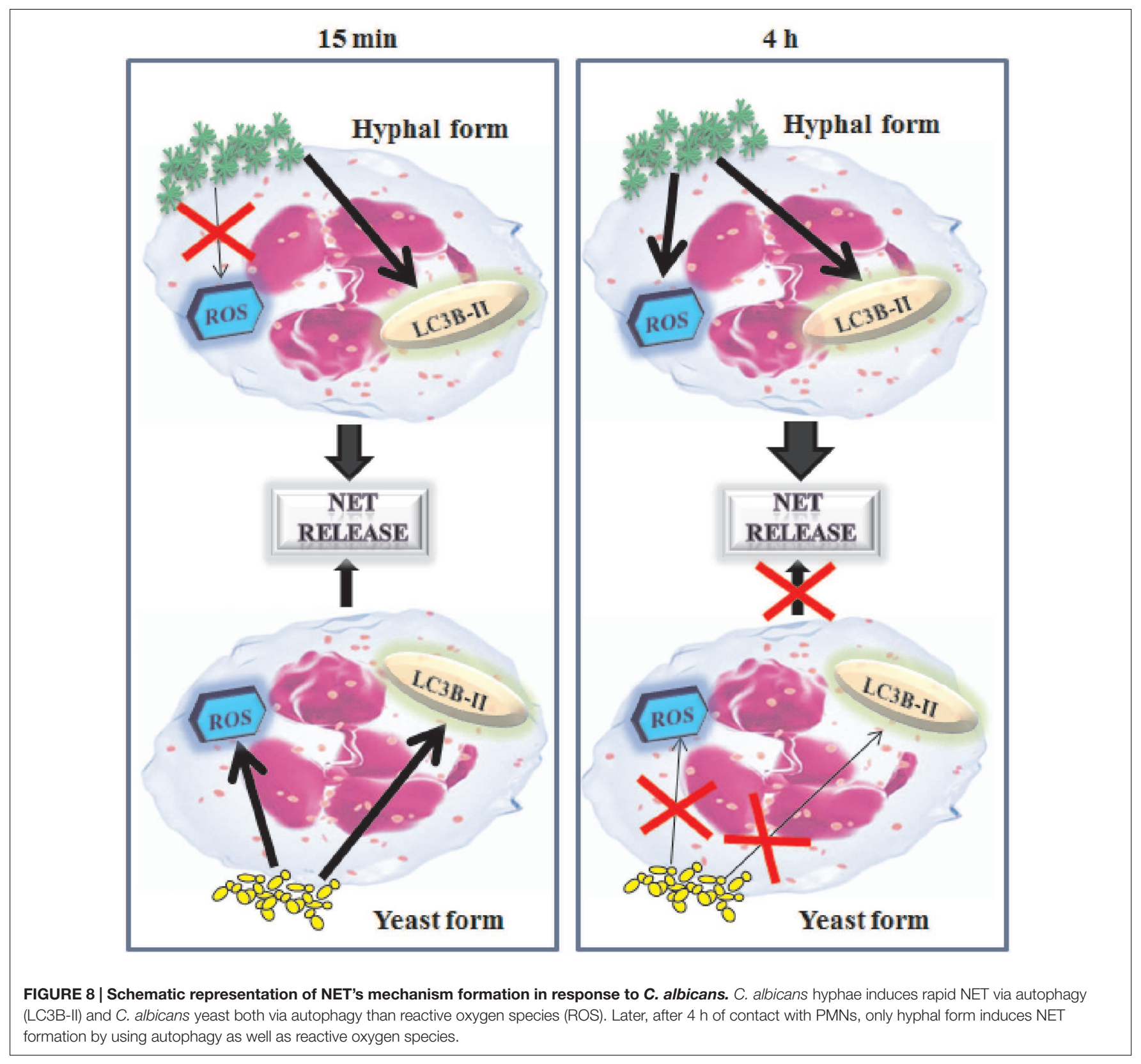

percentage of Candida yeast is killed by NET, and that NET is generated in response to inactivated yeast, it is conceivable that NET is released not, only, to kill microorganisms, but, also, to prevent dissemination of microorganisms by trapping them or for other unknown function. This is consistent with a recent paper demonstrating that, indeed, the trapped microorganisms could be alive (Menegazzi et al., 2012).

Collectively our data show that, both C. albicans morphotypes induce rapid NETs formation. In a early phase (15 min) autophagy plays an important role in inducing NETs in response to hyphae and collaborate with ROS in inducing NET in response to yeast. Lately $(4 \mathrm{~h})$ autophagy and ROS are involved in NETs release in response to hyphae, while, at this time NETs is undetectable in response to yeast and an inducible soluble factor could be involved in this phenomenon. Importantly, NET is implicated in hyphal killing, but retains a marginal role in destroying yeast cells. These results provide evidence that the C. albicans, yeast and hyphae, drive distinct kinetics and mechanisms of NET induction and suggest that the inhibition of NET by live yeast cells, in a $4 \mathrm{~h}$, could be due to a release of soluble factor generated during Candida-neutrophils contact.

\section{AUTHOR CONTRIBUTIONS}

SK: Designed, performed experiments, and analyzed data. SP: designed experiments and analyzed data. 
PM: designed and performed experiments. AV: designed experiments, analyzed data, and wrote the paper. CM: designed experiments, analyzed data, and wrote the paper.

\section{REFERENCES}

Babior, B. M. (1999). NADPH oxidase: an update. Blood 93, 1464-1476.

Barth, S., Glick, D., and Macleod, K. F. (2010). Autophagy: assays and artifacts. J. Pathol. 221, 117-124. doi: 10.1002/path.2694

Birmingham, C. L., and Brumell, J. H. (2006). Autophagy recognizes intracellular Salmonella enterica serovar Typhimurium in damaged vacuoles. Autophagy 2, 156-158. doi: 10.4161/auto.2825

Blommaart, E. F., Krause, U., Schellens, J. P., Vreeling-Sindelarova, H., and Meijer, A. J. (1997). The phosphatidylinositol 3-kinase inhibitors wortmannin and LY294002 inhibit autophagy in isolated rat hepatocytes. Eur. J. Biochem. 243, 240-246. doi: 10.1111/j.1432-1033.1997.0240a.x

Boone, B. A., Orlichenko, L., Schapiro, N. E., Loughran, P., Gianfrate, G. C., Ellis, J. T., et al. (2015). The receptor for advanced glycation end products (RAGE) enhances autophagy and neutrophil extracellular traps in pancreatic cancer. Cancer Gene Ther. 22, 326-334. doi: 10.1038/cgt.2015.21

Branzk, N., Lubojemska, A., Hardison, S. E., Wang, Q., Gutierrez, M. G., Brown, G. D., et al. (2014). Neutrophils sense microbe size and selectively release neutrophil extracellular traps in response to large pathogens. Nat. Immunol. 15, 1017-1025. doi: 10.1038/ni.2987

Brinkmann, V., Reichard, U., Goosmann, C., Fauler, B., Uhlemann, Y., Weiss, D. S., et al. (2004). Neutrophil extracellular traps kill bacteria. Science 303, 1532-1535. doi: $10.1126 /$ science. 1092385

Brinkmann, V., and Zychlinsky, A. (2007). Beneficial suicide: why neutrophils die to make NETs. Nat. Rev. Microbiol. 5, 577-582. doi: 10.1038/nrmicro1710

Bruns, S., Kniemeyer, O., Hasenberg, M., Aimanianda, V., Nietzsche, S., Thywissen, A., et al. (2010). Production of extracellular traps against Aspergillus fumigatus in vitro and in infected lung tissue is dependent on invading neutrophils and influenced by hydrophobin RodA. PLoS Pathog 6:e1000873. doi: 10.1371 /journal.ppat.1000873

Byrd, A. S., O'Brien, X. M., Johnson, C. M., Lavigne, L. M., and Reichner, J. S. (2013). An extracellular matrix-based mechanism of rapid neutrophil extracellular trap formation in response to Candida albicans. J. Immunol. 190, 4136-4148. doi: 10.4049/jimmunol.1202671

Chen, Y., and Junger, W. G. (2012) Measurement of oxidative burst in neutrophils. Methods Mol. Biol. 844, 115-124. doi: 10.(1007)/978-1-61779-527-5_8

Cheng, S. C., Joosten, L. A., Kullberg, B. J., and Netea, M. G. (2012). Interplay between Candida albicans and the mammalian innate host defense. Infect. Immun. 80, 1304-1313. doi: 10.1128/IAI.06146-6111

Diacovich, L., and Gorvel, J. P. (2010). Bacterial manipulation of innate immunity to promote infection. Nat. Rev. Microbiol. 8, 117-128. doi: 10.1038/nrmicro2295

Enjalbert, B., Rachini, A., Vediyappan, G., Pietrella, D., Spaccapelo, R., Vecchiarelli, A., et al. (2009). A multifunctional, synthetic Gaussia princeps luciferase reporter for live imaging of Candida albicans infections. Infect. Immun. 77, 4847-4858. doi: 10.1128/IAI.00223-229

Ermert, D., Niemiec, M. J., Rohm, M., Glenthoj, A., Borregaard, N., and Urban, C. F. (2013). Candida albicans escapes from mouse neutrophils. J. Leukoc. Biol. 94, 223-236. doi: 10.1189/jlb.0213063

Ermert, D., Urban, C. F., Laube, B., Goosmann, C., Zychlinsky, A., and Brinkmann, V. (2009). Mouse neutrophil extracellular traps in microbial infections. J. Innate. Immun. 1, 181-193. doi: 10.1159/000 205281

Fuchs, T. A., Abed, U., Goosmann, C., Hurwitz, R., Schulze, I., Wahn, V., et al. (2007). Novel cell death program leads to neutrophil extracellular traps. J. Cell Biol. 176, 231-241. doi: 10.1083/jcb.200606027

Giraldo, E., Martin-Cordero, L., Hinchado, M. D., Garcia, J. J., and Ortega, E. (2010). Role of phosphatidylinositol-3-kinase (PI3K), extracellular signalregulated kinase (ERK) and nuclear transcription factor kappa beta (NF-k beta) on neutrophil phagocytic process of Candida albicans. Mol. Cell. Biochem. 333, 115-120. doi: 10.1007/s11010-009-0211-215

\section{FUNDING}

This work was supported by the "Fondazione Cassa di Risparmio" of Perugia, Italy (grant No. 2014.0221.021).

Gow, N. A. (2002). Candida albicans switches mates. Mol. Cell. 10, 217-218. doi: 10.1016/S1097-2765(02)00608-1

Gutierrez, M. G., Master, S. S., Singh, S. B., Taylor, G. A., Colombo, M. I., and Deretic, V. (2004). Autophagy is a defense mechanism inhibiting BCG and Mycobacterium tuberculosis survival in infected macrophages. Cell 119, 753-766. doi: 10.1016/j.cell.2004.11.038

Horn, D. L., Ostrosky-Zeichner, L., Morris, M. I., Ullmann, A. J., Wu, C., Buell, D. N., et al. (2010). Factors related to survival and treatment success in invasive candidiasis or candidemia: a pooled analysis of two large, prospective, micafungin trials. Eur. J. Clin. Microbiol. Infect. Dis. 29, 223-229. doi: 10.1007/s10096-009-0843-840

Kanayama, M., and Shinohara, M. L. (2016). Roles of autophagy and autophagy-related proteins in antifungal immunity. Front. Immunol. 7:47. doi: 10.3389/fimmu.2016.00047

Kirchner, T., Moller, S., Klinger, M., Solbach, W., Laskay, T., and Behnen, M. (2012). The impact of various reactive oxygen species on the formation of neutrophil extracellular traps. Mediators Inflamm. 2012:849136. doi: $10.1155 / 2012 / 849136$

Kroemer, G., Galluzzi, L., Vandenabeele, P., Abrams, J., Alnemri, E. S., Baehrecke, E. H., et al. (2009). Classification of cell death: recommendations of the nomenclature committee on cell death. Cell Death. Differ. 16, 3-11. doi: $10.1038 /$ cdd 2008.150

Lapponi, M. J., Carestia, A., Landoni, V. I., Rivadeneyra, L., Etulain, J., Negrotto, S., et al. (2013). Regulation of neutrophil extracellular trap formation by anti-inflammatory drugs. J. Pharmacol. Exp. Ther. 345, 430-437. doi: 10.1124/jpet.112.202879

Levine, B., and Kroemer, G. (2008). Autophagy in the pathogenesis of disease. Cell 132, 27-42. doi: 10.1016/j.cell.2007.12.018

Ling, Y. M., Shaw, M. H., Ayala, C., Coppens, I., Taylor, G. A., Ferguson, D. J., et al. (2006). Vacuolar and plasma membrane stripping and autophagic elimination of Toxoplasma gondii in primed effector macrophages. J. Exp. Med. 203, 2063-2071. doi: 10.1084/jem.20061318

Matoszka, N., Dzialo, J., Tokarz-Deptula, B., and Deptula, W. (2012). [NET and NETosis-new phenomenon in immunology]. Postepy Hig. Med. Dosw. 66, 437-445. doi: 10.5604/17322693.1001178

Menegazzi, R., Decleva, E., and Dri, P. (2012). Killing by neutrophil extracellular traps: fact or folklore? Blood 119, 1214-1216. doi: 10.1182/blood-2011-07364604

Monari, C., Kozel, T. R., Bistoni, F., and Vecchiarelli, A. (2002). Modulation of $\mathrm{C} 5 \mathrm{aR}$ expression on human neutrophils by encapsulated and acapsular Cryptococcus neoformans. Infect. Immun. 70, 3363-3370. doi: 10.1128/IAI.70.7.3363-3370.2002

Nakagawa, I., Amano, A., Mizushima, N., Yamamoto, A., Yamaguchi, H., Kamimoto, T., et al. (2004). Autophagy defends cells against invading group a Streptococcus. Science 306, 1037-1040. doi: 10.1126/science.1103966

Nathan, C. (2006). Neutrophils and immunity: challenges and opportunities. Nat. Rev. Immunol. 6, 173-182. doi: 10.1038/nri1785

Nicola, A. M., Albuquerque, P., Martinez, L. R., Dal-Rosso, R. A., Saylor, C., De Jesus, M., et al. (2012). Macrophage autophagy in immunity to Cryptococcus neoformans and Candida albicans. Infect. Immun. 80, 3065-3076. doi: 10.1128/IAI.00358-312

Nitsche, B. M., Burggraaf-van Welzen, A. M., Lamers, G., Meyer, V., and Ram, A. F. (2013). Autophagy promotes survival in aging submerged cultures of the filamentous fungus Aspergillus niger. Appl. Microbiol. Biotechnol. 97, 82058218. doi: 10.1007/s00253-013-4971-4971

Pietrella, D., Enjalbert, B., Zeidler, U., Znaidi, S., Rachini, A., Vecchiarelli, A., et al. (2012). A luciferase reporter for gene expression studies and dynamic imaging of superficial Candida albicans infections. Methods Mol. Biol. 845, 537-546. doi: 10.1007/978-1-61779-539-8_39

Pilsczek, F. H., Salina, D., Poon, K. K., Fahey, C., Yipp, B. G., Sibley, C. D., et al. (2010) A novel mechanism of rapid nuclear neutrophil extracellular trap 
formation in response to Staphylococcus aureus. J. Immunol. 185, 7413-7425. doi: 10.4049/jimmunol.1000675

Remijsen, Q., Vanden Berghe, T., Wirawan, E., Asselbergh, B., Parthoens, E., De Rycke, R., et al. (2011). Neutrophil extracellular trap cell death requires both autophagy and superoxide generation. Cell Res. 21, 290-304. doi: $10.1038 / \mathrm{cr} .2010 .150$

Safdar, A., Rodriguez, G., Rolston, K. V., O’Brien, S., Khouri, I. F., Shpall, E. J., et al. (2007). High-dose caspofungin combination antifungal therapy in patients with hematologic malignancies and hematopoietic stem cell transplantation. Bone Marrow Transplant. 39, 157-164. doi: 10.1038/sj.bmt.170 5559

Steinberg, B. E., and Grinstein, S. (2007). Unconventional roles of the NADPH oxidase: signaling, ion homeostasis, and cell death. Sci. STKE 2007:pe11. doi: 10.1126/stke.3792007pe11

Urban, C. F., Ermert, D., Schmid, M., Abu-Abed, U., Goosmann, C., Nacken, W., et al. (2009). Neutrophil extracellular traps contain calprotectin, a cytosolic protein complex involved in host defense against Candida albicans. PLoS Pathog. 5:e1000639. doi: 10.1371/journal.ppat.1000639

Urban, C. F., Reichard, U., Brinkmann, V., and Zychlinsky, A. (2006). Neutrophil extracellular traps capture and kill Candida albicans yeast and hyphal forms. Cell. Microbiol. 8, 668-676. doi: 10.1111/j.1462-5822.2005.00659.x

van 't Wout, J. W., Linde, I., Leijh, P. C., and van Furth, R. (1988). Contribution of granulocytes and monocytes to resistance against experimental disseminated Candida albicans infection. Eur. J. Clin. Microbiol. Infect. Dis. 7, 736-741. doi: 10.1007/BF01975039

Van't Wout, J. W., Van der Meer, J. W., Barza, M., and Dinarello, C. A. (1988). Protection of neutropenic mice from lethal Candida albicans infection by recombinant interleukin 1. Eur. J. Immunol. 18, 1143-1146. doi: 10.1002/eji.1830180728

Vecchiarelli, A., Mazzolla, R., Farinelli, S., Cassone, A., and Bistoni, F. (1988). Immunomodulation by Candida albicans: crucial role of organ colonization and chronic infection with an attenuated agerminative strain of $\mathrm{C}$. albicans for establishment of anti-infectious protection. J. Gen. Microbiol. 134, 2583-2592. doi: 10.1099/00221287-134-9-2583

Vecchiarelli, A., Pietrella, D., Dottorini, M., Monari, C., Retini, C., Todisco, T., et al. (1994). Encapsulation of Cryptococcus neoformans regulates fungicidal activity and the antigen presentation process in human alveolar macrophages. Clin. Exp. Immunol. 98, 217-223. doi: 10.1111/j.1365-2249.1994.tb06128.x

Wang, Y., Li, M., Stadler, S., Correll, S., Li, P., Wang, D., et al. (2009). Histone hypercitrullination mediates chromatin decondensation and neutrophil extracellular trap formation. J. Cell Biol. 184, 205-213. doi: $10.1083 /$ jcb. 200806072

Whiteway, M., and Oberholzer, U. (2004). Candida morphogenesis and host-pathogen interactions. Curr. Opin. Microbiol. 7, 350-357. doi: 10.1016/j.mib.2004.06.005

Wozniok, I., Hornbach, A., Schmitt, C., Frosch, M., Einsele, H., Hube, B., et al. (2008). Induction of ERK-kinase signalling triggers morphotype-specific killing of Candida albicans filaments by human neutrophils. Cell Microbiol. 10, 807820. doi: 10.1111/j.1462-5822.2007.01086.x

Wu, Y. T., Tan, H. L., Shui, G., Bauvy, C., Huang, Q., Wenk, M. R., et al. (2010). Dual role of 3-methyladenine in modulation of autophagy via different temporal patterns of inhibition on class I and III phosphoinositide 3-kinase. J. Biol. Chem. 285, 10850-10861. doi: 10.1074/jbc.M109.080796

Yang, Y. P., Hu, L. F., Zheng, H. F., Mao, C. J., Hu, W. D., Xiong, K. P., et al. (2013). Application and interpretation of current autophagy inhibitors and activators. Acta Pharmacol. Sin. 34, 625-635. doi: 10.1038/aps.2013.5

Young, R. L., Malcolm, K. C., Kret, J. E., Caceres, S. M., Poch, K. R., Nichols, D. P., et al. (2011). Neutrophil extracellular trap (NET)-mediated killing of Pseudomonas aeruginosa: evidence of acquired resistance within the CF airway, independent of CFTR. PLOS ONE 6:e23637. doi: 10.1371/journal.pone.0023637

Conflict of Interest Statement: The authors declare that the research was conducted in the absence of any commercial or financial relationships that could be construed as a potential conflict of interest.

Copyright (c) 2016 Kenno, Perito, Mosci, Vecchiarelli and Monari. This is an openaccess article distributed under the terms of the Creative Commons Attribution License (CC BY). The use, distribution or reproduction in other forums is permitted, provided the original author(s) or licensor are credited and that the original publication in this journal is cited, in accordance with accepted academic practice. No use, distribution or reproduction is permitted which does not comply with these terms. 